\title{
Relationship between Corrected QT Interval (QTc) Prolongation and Insulin Resistance in Obese Adult Male Subjects
}

\author{
Zarchi Theint Theint Hlaing, Soe Minn Htway, Mya Thanda Sein
}

\section{ABSTRACT}

QT Interval prolongation is common in insulin resistance state obesity. Insulin-induced hyperpolarization might be involved in ventricular repolarization leading to QTc lengthening. Therefore, this study is designated to investigate the relationship between corrected QT interval (QTe) prolongation and insulin resistance in obese adult male subjects. Apparently healthy adult male subjects $(n=100)$ aged between 18-35 years residing in Magway Township were recruited by simple random sampling method. Then all the eligible subjects were categorized into 2 groups: nonobese [body mass index (BMI) 18.5 to $24.9 \mathrm{~kg} / \mathrm{m} 2, \mathrm{n}=40$ ] and obese group $[B M I \geq 30.0 \mathrm{~kg} / \mathrm{m} 2, \mathrm{n}=60]$ by their anthropometric parameters. Serum fasting glucose was measured by glucose oxidase method. Serum insulin level was determined by Enzyme-Linked Immunosorbent Assay (ELISA). Insulin sensitivity was calculated by Homeostatic Model Assessment (HOMA-IR). The QT interval was measured by routine 12-lead ECG and corrected QT interval (QTc) was calculated according to Bazett's formula. In the present study, insulin sensitivity (HOMA-IR) was higher in obese subjects $(4.64 \pm 2.3)$ than that of non-obese subjects $(2.5 \pm 0.89)(\mathrm{p}<0.001)$. There was significant positive correlation between QTc and HOMA-IR ( $r=$ $0.41, \mathrm{p}<0.001, \mathrm{n}=100$ ) in this study. HOMA-IR $>3.8$ was considered as insulin resistance (IR) and QTe $>440 \mathrm{~ms}$ was regarded as QTe interval prolongation. Insulin resistance was significantly associated with prolonged QTe interval in the study population (X2=7.3, $\mathrm{p}<0.05, \mathrm{n}=100)$. Risk of QTe interval prolongation was 3.4 times higher in subjects with IR $($ Odd ratio $=$ $3.4 ; 95 \%$ confidence interval $=1.37$ to 8.45$)$. It was concluded that prolonged QTc interval is associated with insulin resistance state.

Keywords: Body Mass Index; Insulin resistance; Obesity; QTc prolongation.

\section{INTRODUCTION}

QT interval is the time from the start of the Q wave to the end of the $\mathrm{T}$ wave. It represents both ventricular depolarization and repolarization. It can be measured by routine 12-lead ECG with lead II rhythm strip for 10 seconds [1]. QTc is the corrected QT interval with heart rate of 60 beats/min. It was calculated by Bazett's formula [2].

$$
Q T c(m s)=\frac{Q T(m s)}{\sqrt{R-R(s)}}
$$

QTc value between $350-420 \mathrm{~ms}$ is regarded as normal QT interval and its value more than $420 \mathrm{~ms}$ indicates prolonged QT interval [3]. Prolonged QTc interval is the representation of delayed ventricular repolarization, and it can be the risk factor for the development of ventricular tachyarrhythmias, syncope and sudden cardiac death [4]-[6]. Some studies reported an association between QT interval and cardiac risk factors and mortality [7], [8].
Published Online: January 14, 2021

ISSN: 2593-8339

DOI: $10.24018 /$ ejmed.2021.3.1.655

Zarchi Theint Theint Hlaing* University of Medicine, Magway, Myanmar.

(e-mail: zarchi.tth@gmail.com) Soe Minn Htway

University of Medicine, Magway, Myanmar.

(e-mail: drsmhtway@gmail.com)

Mya Thanda Sein

University of Medicine-1, Yangon, Myanmar.

(e-mail: dr.myathandasein@gmail.com)

*Corresponding Author
There are some evidence demonstrating the relationship between insulin sensitivity and QTc in type 2 diabetes [9], [10]. Insulin resistance means the inability of insulin to produce its usual biological actions at circulating concentrations which are effective in normal subject. Hyperinsulinemia is usually a condition to compensate the insulin resistance [11]. One of physiological action of insulin is increased permeability of many cells to potassium. Insulin increased resting membrane potential of excised rat muscle [12]. Insulin hyperpolarizes plasma membranes and affects ventricular repolarization [13]. There is little information about the relationship between QTc and insulin resistance in obesity since obesity is hyperglycemic and hyperinsulinemic state. Therefore, this study was designated to investigate the relationship between QTc prolongation and insulin resistance in obese adult male subjects. 


\section{MATERIAL AND METHODS}

Apparently healthy adult male subjects $(n=100)$ aged between 18-35 years residing in Magway Township were recruited according to inclusion and exclusion criteria. Subjects with history of heart disease, diabetes mellitus, current smoker and current alcoholic were excluded. Apparently healthy adult male subjects were selected by simple random sampling method. The procedure was explained and written informed consent was obtained. Anthropometric measurement was done at Ward Administrator Office. Then all the eligible subjects were categorized into 2 groups: non-obese [body mass index (BMI) 18.5 to $24.9 \mathrm{~kg} / \mathrm{m}^{2}, \mathrm{n}=40$ ] and obese group [BMI $\geq$ $\left.30.0 \mathrm{~kg} / \mathrm{m}^{2}, \mathrm{n}=60\right]$ by their anthropometric parameters. Fasting blood sample $(5 \mathrm{ml})$ was taken from antecubital vein under aseptic condition by using a disposable syringe and needle for each subject. Blood will be collected in two separate blood collecting tubes: one $\mathrm{ml}$ of blood will be collected in tube containing $10 \mathrm{mg}$ of sodium fluoride for determination of blood sugar and $4 \mathrm{ml}$ of blood in another tube for serum separation. The blood sample was allowed to clot for 30 minutes at room temperature and centrifuged for 15 minutes at $3000 \mathrm{rpm}$. Serum will be separated and collected in sample tubes and stored at $\left(-20^{\circ} \mathrm{C}\right)$ until the blood sample analysis. Serum glucose level was determined on the same day of blood collection. Serum fasting glucose was measured by glucose oxidase method and serum insulin level was measured by enzyme linked immunoassay (ELISA) kit method. Insulin sensitivity was calculated by following formula (HOMA: Homeostatic Model Assessment) [14].

$$
H O M A-I R=\frac{\operatorname{Insulin}(\mu I U / \mathrm{mL}) \times \text { glucose }(\mathrm{mmol} / \mathrm{L})}{22.5}
$$

HOMA-IR >3.8 is considered as insulin resistance state.

After 15 minute rest, routine 12-lead ECG was also performed. Lead II rhythm strip for 10 seconds was taken. The R-R intervals and QT intervals were measured. Corrected QT interval (QTc) was calculated using Bazett's formula [2]. Data were analyzed by using SPSS software for Window. All data were expressed as mean \pm SD. Statistical analysis of the two sets of data (non-obese group and obese group) was carried out by independent student $\mathrm{t}$ Test. Correlation studies were computed by Pearson's correlation. Differences were considered significant when $\mathrm{P}<0.05$.

\section{RESULTS}

Table 1 showed the general characteristics of the subjects. Fig. 1 indicated the comparison of HOMA-IR values between non-obese and obese subjects. Fig. 2 point out the comparison of QTc interval in non-obese and obese subjects. There was significant positive correlation between insulin sensitivity and QTc (Fig. 3). Table 2 specified Odd ratio of QTc prolonged in normal and insulin resistance subjects.
TABLE 1: Characteristics of the subjects (Mean \pm SD)

\begin{tabular}{ccc}
\multicolumn{3}{c}{ TABLE 1: Characteristics of the subjects $($ Mean $\pm \mathrm{SD})$} \\
\hline & Non-obese & Obese \\
& $(\mathrm{n}=40)$ & $(\mathrm{n}=60)$ \\
& $($ Mean $\pm \mathrm{SD})$ & $($ Mean $\pm \mathrm{SD})$ \\
\hline Age (years) & $22.30 \pm 1.77$ & $23.50 \pm 2.24$ \\
Weight $(\mathrm{kg})$ & $59.70 \pm 4.21$ & $85.53 \pm 8.37$ \\
Height $(\mathrm{m})$ & $1.62 \pm 0.49$ & $1.65 \pm 0.06$ \\
BMI $\left(\mathrm{kg} / \mathrm{m}^{2}\right)$ & $22.91 \pm 1.11$ & $31.68 \pm 1.76$ \\
\hline
\end{tabular}

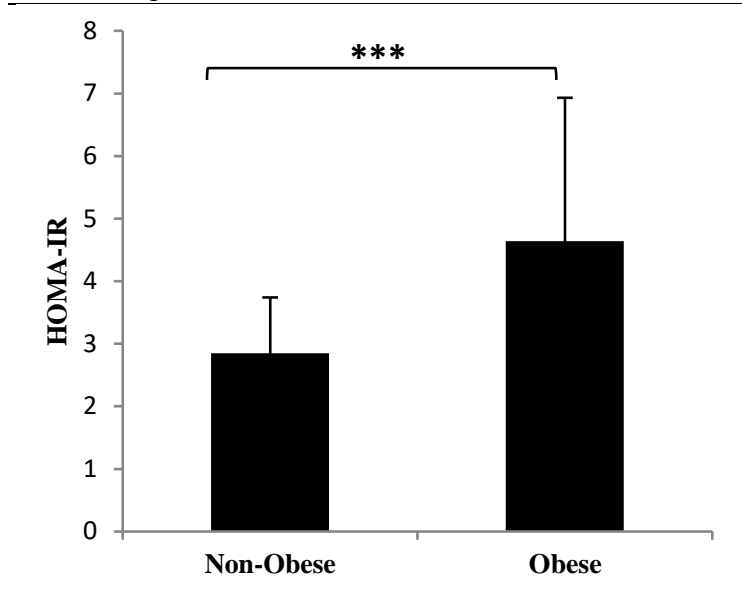

Fig. 1. Comparison of HOMA-IR values between non-obese and obese subjects.

$* * *$ indicates significant difference at $\mathrm{p}<0.001$.

NB: Comparison was done by independent student $t$ test.

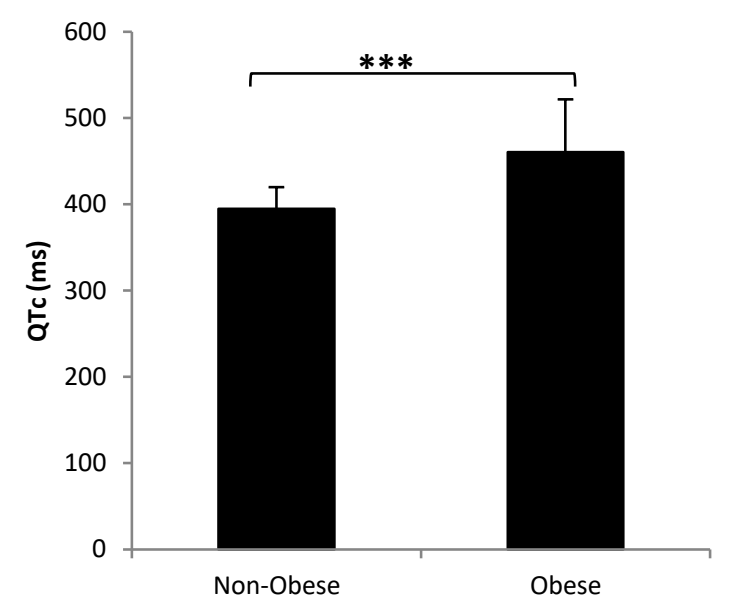

Fig. 2. QTc of non-obese and obese subjects.

$* * *$ indicates significant difference at $\mathrm{p}<0.001$

$\mathrm{NB}$ : Comparison was done by independent student $\mathrm{t}$ test.

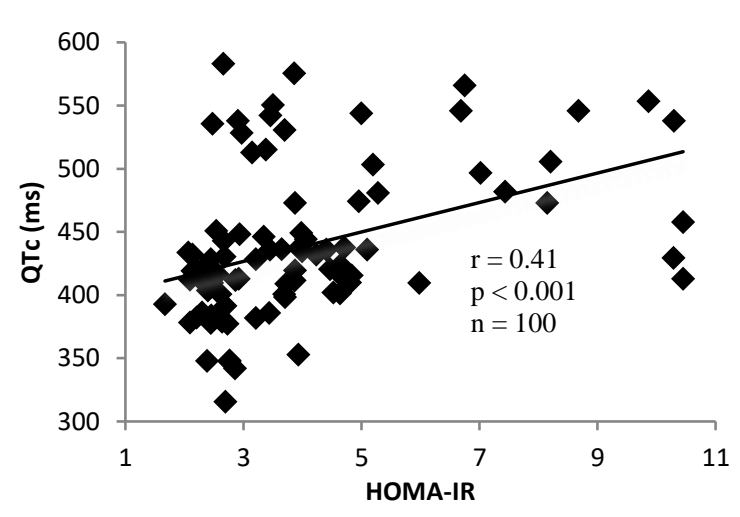

Figure 3. Correlation between insulin sensitivity and QTc. QTc = corrected QT interval.

HOMA-IR = insulin sensitivity.

$\mathrm{r}=$ Pearson's correlation coefficient.

$\mathrm{n}=$ total number of subjects 
TABLE 2: ODD RATIO OF QTC PROLONGED IN NORMAL AND INSULIN RESISTANCE SUBJECTS

\begin{tabular}{ccccc}
\multicolumn{4}{c}{ RESISTANCE SUBJECTS } \\
\hline $\begin{array}{c}\text { Normal } \\
\text { QTc } \\
(\text { QTe }<440 \mathrm{~ms})\end{array}$ & $\begin{array}{c}\text { QTc prolonged } \\
(\mathrm{QTc}>440 \mathrm{~ms})\end{array}$ & $\begin{array}{c}\text { Odd } \\
\text { ratio }\end{array}$ & $\begin{array}{c}95 \% \\
\text { CI }\end{array}$ \\
\hline $\begin{array}{c}\text { Normal (HOMA- } \\
\text { IR }<3.8) \\
\text { Insulin }\end{array}$ & 54 & 14 & & \\
Resistance & 17 & 15 & 3.4 & $\begin{array}{c}1.37 \\
\text { to } \\
(\text { HOMA-IR }>3.8)\end{array}$ \\
\hline
\end{tabular}

\section{DISCUSSION}

In the present study, the fasting blood glucose level of obese subjects was $5.01 \pm 0.43 \mathrm{mmol} / \mathrm{L}$ and that of non-obese subjects was $4.68 \pm 0.34 \mathrm{mmol} / \mathrm{L}(\mathrm{p}<0.05)$. Serum insulin level of obese subjects $(21.96 \pm 2.76 \mu \mathrm{LU} / \mathrm{mL})$ was significantly higher than that of non-obese subjects $(13.7 \pm 4.16 \mu \mathrm{LU} / \mathrm{mL})(\mathrm{p}<0.05)$. Although fasting blood glucose of all non-obese and obese subjects who participated in this study had within normal range (fasting plasma glucose: 3.5 to $6.1 \mathrm{mmol} / \mathrm{L}$ ), the mean HOMA-IR value was higher in obese subjects $(4.64 \pm 2.3)$ than that of non-obese subjects $(2.5 \pm 0.89)(\mathrm{p}<0.001)$. HOMA-IR $>3.8$ was considered as insulin resistance [15]. In addition, 4 out of 40 non-obese subjects had insulin resistant state and 28 out of 60 obese subjects had insulin resistant (Odd ratio = 7.88; $95 \%$ confidence interval $=2.49$ to 24.89 ). The risk of insulin resistance was 7.88 times in obese subjects than nonobese subjects. This study was coincided with other previous studies which had shown that there is a significant strong epidemiological association between obesity and the development of insulin resistance [16-[19]. In the present study, the observed increase in fasting serum insulin in the obese subjects compared with that of the non-obese subjects might be due to a compensatory increase in insulin secretion and thus maintaining the plasma glucose level within the normal range.

In the present study, the QTc of non-obese subjects was $393.7 \pm 22.34 \mathrm{~ms}$ and that of obese subjects was $461.71 \pm 61.85 \mathrm{~ms}(\mathrm{p}<0.001)$. It was consistent with the studies of Corbi et al., Guven et al., Arslan et al., Ozkan et al., Hlaing et al. They reported that the obese group had more prolong QTc than the non-obese group [1], [3], [20][22]. These studies stated that the possible mechanism of the prolonged QTc interval might be due to autonomic dysfunction and increased serum insulin level in obesity. Aleksandra et al. [23] found that the QTc interval was significantly longer in metabolic syndrome patients than in the control group $(411.1 \pm 35.72$ vs. $390.95 \pm 26.31 \mathrm{~ms}$, p $<0.05)$ and there was a statistically significant positive correlation between the length of the QTc interval and HOMA-IR ( $\mathrm{r}=0.38, \quad \mathrm{p}<0.01)$ [23]. There was also significant positive correlation between QTc and HOMA-IR $(\mathrm{r}=0.41, \mathrm{p}<0.001, \mathrm{n}=100)$ in this study. Moreover, insulin resistance was significantly associated with prolonged QTc interval in the study population (X2=7.3, $\mathrm{p}<0.05, \mathrm{n}=100)$. Additionally, 15 out of 32 insulin resistant subjects had prolonged QTc intervals although 14 out of 68 normal subjects had prolonged QTc intervals (Odd ratio $=3.4 ; 95 \%$ confidence interval $=1.37$ to 8.45 ). Therefore, the risk of QTc interval prolongation was 3.4 times higher in subjects with insulin resistance. It was reported that there was the direct effect of exogenous insulin on QTc [13]. In adults, compensatory hyperinsulinemia may lead to persistent QTc lengthening in insulin-resistant patients with obesity, even in the absence of autonomic neuropathy. Insulin causes QTc prolongation directly or through sympathetic activation [24].

These findings support the findings of previous studies. Thus, it can be assumed that the prolonged QTc of obese subjects in the present study might be due to obesity induced hyperinsulinaemia and insulin resistance state. It could be due to the physiological action of insulin by increasing the membrane permeability of the cells and hyperpolarized the plasma membrane that results in prolonged QTc interval.

\section{CONCLUSION}

The risk of the QTc interval prolongation was 3.4 times higher in subjects with insulin resistance. There was a significant positive correlation between QTc and HOMAIR. It can be concluded that compensatory hyperinsulinemia may lead to QTc lengthening in insulin-resistant state obesity.

\section{LIMITATION OF THE STUDY}

As a cross sectional analytical study, it cannot clearly establish the causative effect of insulin resistance on QTc interval. The present study does not explore the autonomic neuropathy which can affect insulin sensitivity.

\section{ACKNOWLEDGMENT}

I would like to thank Professor Aye Aye Oo, Pro-rector, University of Medicine, Magway for sampling method and data analysis. I wish to record my deep sense of thanks to the participants from Magway Township who willingly gave consent to this study.

\section{REFERENCES}

[1] Guven A, Ozgen T, Gungor O, Aydin M and Baysal K.Association between the corrected QT Interval and carotid artery intimal-media thickness in obese children.J Clin Res Ped Endo 2010(1): 21-27.

[2] Bazett HC. An analysis of the time relationships of electrocardiograms. Heart 1920;7:353-357.

[3] Arslan E, Yininer O, Yavasoglul I, Ozcelik F, Kardesoglu E and Nalbant S. Effect of uncomplicated obesity on QT interval in young men.Pol Arch Med Wewn 2010; 120(6): 209-213.

[4] Vlay SC, Mallis GI, Brown EJ, Cohn PF. Documented sudden cardiac death in prolonged QT syndrome. Arch Intern Med 1984;144: 833 835 .

[5] Giraldi FP, Manzonil G, Michailidis J, Scacchi M, Stramba-Badiale $M$ and Cavagnini F. High prevalence of prolonged QT interval in obese hypogonadal males. Obesity 2011;19: 2015-2018.

[6] Milovancev A, Stokic E, Popovic DS, Naglic DT, Rankov O.Body Weight Reduction and QTc Interval in Obesity.Adv Weigh Loss Manag Med Dev 2016;1:102. doi:10.4172/AWMD.1000102.

[7] Dekker, J.M., Crow, R.S., Hannan, P.J., Schouten, E.G. and Folsom, A.R. Heart rate corrected QT interval prolongation predicts risk of coronary heart diseases in black and white middle-aged men and women. Journal of the American College of Cardiology 2004; 43(4): 565-636.

[8] Straus, S.M.J.M., Kors, J.A., Bruin, M.L.D., van der Hoof, C.S., Hofman, A., Heeringa, J., Decker, J.W., Kingma, J.H., Sturkenboom, M.C.J.M., Stricker, B.H.C. and Witteman, J.C.M. Prolong QTc interval and risk of sudden cardiac death in a population of older 
adults. Journal of the American College of Cardiology 2006; 47(2): 362-369

[9] Festa A, D'Agostino R Jr, Rautaharju P, Mykkanen L, Haffner SM. Relation of systemic blood pressure, left ventricular mass, insulin sensitivity, and coronary artery disease to QT interval duration in nondiabetic and type 2 diabetic subjects. Am J Cardiol. 2000; 86(10):1117-22.

[10] Yang X, Su J, Zhang X, Zhao L, Xu F, Wang X, Cheng X. The relationship between insulin sensitivity and heart rate- corrected QT interval in patients with type 2 diabetes. Diabetol Metab Syndr 2017; 9(69): 1-9.

[11] Himsworth, H.P. Diabetes mellitus; its differentiation into insulin sensitive and insulin insensitive types. Lancet, 1936; 1:127-30.

[12] Zierler K. Effect of insulin on membrane potential and potassium content of rat muscle. Am J Physiol 1959;197: 515-523.

[13] Gastaldelli A, Emdin M, Conforti F, Camastra S and Ferrannini E. Insulin prolongs the QTc interval in humans. Am J Physiol Regul Integr Comp Physiol 2000; 279: 2022-2025.

[14] Matthews, D.R., Hosker, J.P., Rudenski, A.S., Naylor, B.A., Treacher, D.F. and Turner, R.C. Homeostasis model assessment: insulin resistance and $\beta$ cell function from fasting plasma glucose and insulin concentration in man. Diabetiologia 1985; 28, p. 412-9.

[15] Qu HQ, Li Q, Rentfro AR, Fisher-Hoch SP, McCormick JB. The definition of insulin resistance using HOMA-IR for Americans of Mexican descent using machine learning. PloS one, 2011; 6(6).

[16] Bogardus C, Lillioja S, Mott D, Reaven GR, Kashiwagi A and Foley JE. Relationship between obesity and maximal insulin-stimulated glucose uptake in vivo and in vitro in Pima Indians. J Clin Invest. 1984; 73(3):800-805.

[17] Ferrannini E, Natali A, Bell P, Cavallo-Perin P, Lalic N and Mingrone G. Insulin resistance and hypersecretion in obesity. European Group for the Study of Insulin Resistance (EGIR). J Clin Invest. 1997;100(5):1166-1173.

[18] Greco, A.V., Mingrone, G., Giancaterini, A., Manco, M., Morroni, M., Cinti, S., Granzotto, M., Vettor, R., Camastra, S. and Ferrannini, E. (2002) Insulin resistance in morbid obesity. Diabetes, 51, p. 14451.

[19] Camastra, S.,.Manco, M., Mari, A., Baldi, S., Gastaldelli, A., Greco, A.V., Mingrone, G. and .Ferrannini, E. (2005) Beta cell function in morbidly obese subjects during free living. Diabetes, 54, p. 2382-89.

[20] Corbi GM, Carbone S, Ziccardi P, Giugliano G, Marfella R, Nappo F, Paolisso G, Esposito K and Giugiano D. FFAs and QT intervals in obese women with visceral adiposity: effects of sustained weight loss over 1 year. Journal of Clinical Endocrinology \& Metabolism 2002; 87(5): 2080-2083.

[21] Ozkan EA, Khosroshahi HE, Serin HI, Ozdamir ZT, Kilic M, Gecit UA and Ekim M. Evaluation of QTc Value and Relation Between QTc Interval and Cardiovascular Risk Factors in Obese Children. American Journal of Health 2015; 3(3): 194-197.

[22] Hlaing ZTT, Hway SM, Yee NN, Sein MT. Serum testosterone level and corrected QT interval (QTc) in non-obese and obese adult male subjects. EC Cardiology 2018; 5(11):805-817.

[23] Aleksandra M, Stokic E, Plecas-Duric A, Popovic D and Ilincic B. Is QTc interval associated with insulin resistance in metabolic syndrome? Cardiology and cardiovascular medicine 2016; 1(1): 2636.

[24] Frank S, Colliver JA, Frank A. The electrocardiogram in obesity: statically analysis of 1029 patients. J Am Coll Cardiol 1986; 7: 295299.

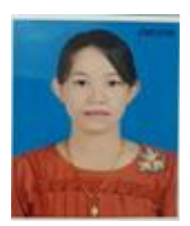

\section{Zarchi Theint Theint Hlaing}

M.B.B.S, M.Med.Sc, Ph.D (Physiology), Dip. Med. Ed Lecturer, Department of Physiology,University of Medicine, Magway, Myanmar.

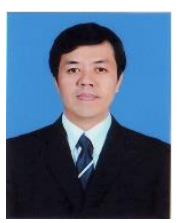

\section{Soe Minn Htway}

M.B.B.S, M.Med.Sc, Ph.D (Physiology), Dip. Med. Ed. Professor and Head, Department of Physiology, University of Medicine, Magway, Myanmar.

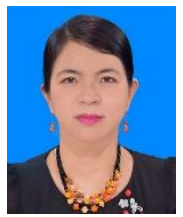

Mya Thanda Sein

M.B.B.S, M. Med. Sc, Ph. D (Physiology), Dip. Med. Ed. Professor and Head, Department of Physiology, University of Medicine-1, Yangon, Myanmar. 